\title{
Outsourcing challenges FDA to strengthen oversight abroad
}

Pharmaceutical companies are increasingly contracting out manufacturing to firms overseas as a way to trim their bottom line. But where pharma sees mostly costsaving solutions, the US Food and Drug Administration (FDA) sees regulatory headaches.

Following a 2008 scandal with a tainted blood thinner imported from China that killed 81 people in the US, the FDA launched its 'beyond our borders' initiative to build relations with foreign governments and regulatory agencies, as well as to improve its own oversight of imported food and medical products. The agency has since opened ten offices abroad, including ones in China, India, Europe and Latin America; the latest post, in Mexico City, opened in December.

The total number of inspectors stationed abroad, however, is limited. Two medical product inspectors operate out of Shanghai, whereas five inspectors for both food and medicine are based in Mumbai, India. As such, most inspections still largely rely upon staff stationed in the US, where only 28 members are dedicated to foreign inspections.

Instead of going on a hiring spree, the FDA is now looking to bolster its partnerships with other regulatory agencies to help fill in the gaps. Last year, the FDA kicked off a two-year pilot project with the European Medicines Agency (EMA) and Australia's Therapeutic Goods Administration (TGA) to jointly coordinate inspections of facilities that prepare active pharmaceutical ingredients and to share completed reports.

Agencies for several European countries joined, and the nine total participating groups tabulated a list of roughly 500 manufacturing sites to inspect, with nearly 200 identified as being common to at least two agencies, says David Cockburn, head of the EMA's manufacturing and quality compliance. Thus far, the project has led to the exchange of 28 inspection reports and the completion of 14 joint inspections, according to EMA records.

"All three organizations" - the FDA, EMA and TGA - "recognize the issues, and all three lack the resources to do this on their own," says Murray Lumpkin, the FDA's deputy commissioner of international programs in Rockville, Maryland.

Aside from sharing reports, the FDA is already piloting a scheme to increase inspection capacity by accrediting independent companies to inspect facilities on the agency's behalf. Currently, the agency

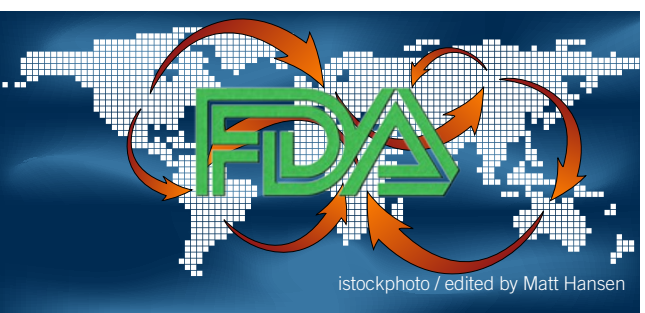

Foreign affairs: Regulator looks beyond its borders

is testing the approach with foreign shrimp providers and medical device manufacturers; Lumpkin says the FDA plans to examine the resulting data before deciding whether to do the same with pharmaceuticals.

Jerry Avorn, a physician-researcher at Harvard Medical School in Boston, has another solution. He says that the agency should exert its authority over the companies importing pharmaceutical ingredients, rather than on the various manufacturers. This would put the onus of inspections on importers, thereby decreasing the FDA's financial and administrative burden.

"The FDA is still horrendously underfunded and understaffed," notes Avorn. With the FDA's foreign inspection budget at $\$ 17$ million in 2008-compared to $\$ 192$ million for domestic inspectionsvast improvements are unreasonable, unless Congress provides further support to the agency, he says.

That support, however, is waiting on the sidelines of Capitol Hill. The proposed FDA Globalization Act, sponsored last year by Congressman John Dingell (Democrat, Michigan), included stipulations for countryof-origin labels, an importer registration system and a larger foreign inspectorate. Portions of the bill were amalgamated into another act, but the rest-those sections dealing with drugs and devices_-were left for later. Dingell plans to turn his attention to the remaining pieces of the act after Congress deals with health care reform, his office says.

Christian Torres, New York

\section{A good year for biologics}

Whereas the total number of new medicines approved by the US Food and Drug Administration inched up only a hair's breadth last year-from 25 in 2008 to 26 in 2009—-the agency gave the green light to more first-of-its-kind therapeutic biologics than ever. Could 2009 have been the year when biotech drugs started to take over

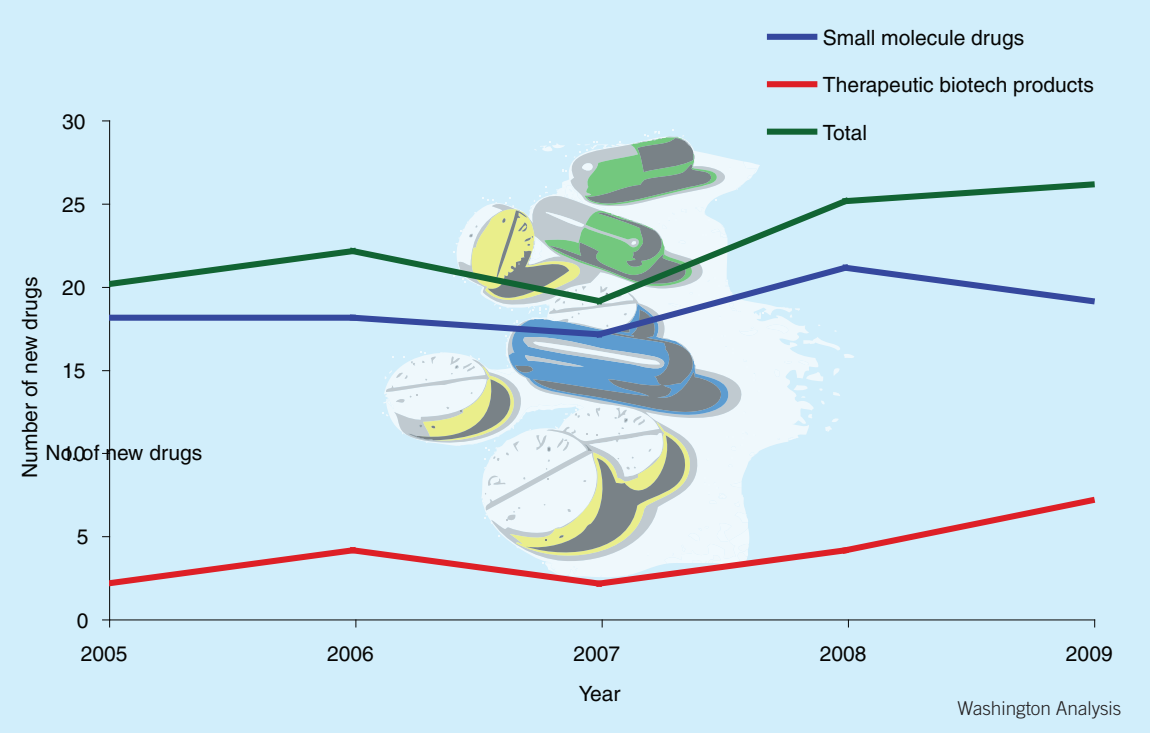

from the small-molecule field? "It is too soon to declare a breakthrough, but this is the direction medicine has been heading for some time, and perhaps the momentum is picking up," Ira Loss, a senior healthcare analyst at the research firm Washington Analysis, told Nature Medicine. "Let's see what happens in 2010." 